\title{
ESTUDO DE VARIABILIDADE DO VENTO EM ESCALA SAZONAL SOBRE O NORDESTE BRASILEIRO UTILIZANDO O RAMS: OS CASOS DE 1973-1974 E 1982-1983
}

\author{
JULIANA LIMA OLIVEIRA ${ }^{1}$ E ALEXANDRE ARAÚJO COSTA ${ }^{2}$ \\ ${ }^{1}$ Fundação Cearense de Meteorologia e Recursos Hídricos (FUNCEME) \\ ${ }^{2}$ Universidade Estadual do Ceará (UECE) \\ oliveirajuu@gmail.com, alexandrearaujoc@gmail.com
}

Recebido Março 2009 - Aceito Março 2010

\begin{abstract}
RESUMO
O propósito deste trabalho é analisar a influência da variabilidade climática e os impactos da circulação geral no comportamento dos ventos sobre o Nordeste do Brasil, com enfoque no modelo atmosférico como uma possível ferramenta para previsão de geração de energia eólica. Análises estatísticas sugerem que há uma correlação bastante significativa entre os índices climáticos (índices de El Niño e dipolo) e a intensidade do vento sobre o Nordeste brasileiro, principalmente nos meses de fevereiro a maio, correspondentes à quadra chuvosa. Dados de reanálise do NCEP para eventos de ENOS fortes (El Niño de 1982-83 e La Niña de 1973-74) sugerem que, nesses casos, a influência da circulação geral é tal que eventos fortes de El Niño e La Niña atuam no sentido de intensificar e enfraquecer, respectivamente, os ventos sobre essa região. Como circulações em menor escala, associadas ao sistema de brisa e à forçantes topográficos são bastante relevantes para determinar as características do vento local, o modelo atmosférico de mesoescala Regional Atmospheric Modeling System (RAMS) foi utilizado para simular a velocidade e direção dos ventos de julho a junho de 1982-83 e 1973-74, a fim de estimar a variabilidade dos ventos em escala sazonal e os possíveis impactos dessas variações na produção de energia eólica no Nordeste.
\end{abstract}

Palavras Chaves: Variabilidade Climática, Modelagem Atmosférica, Energia Eólica

\begin{abstract}
STUDY OF WIND VARIABILITY IN SEASONAL SCALE OVER NORTHEAST BRAZIL USING RAMS: EVENTS OF 1973-1974 AND 1982-1983

The purpose of this work is to analyze the influence of climate variability and general circulation impact on the behavior of the winds over Northeast Brazil, with emphasis in the atmospheric model as a feasible tool for forecasting of wind power generation. Statistical analysis suggest that there is a significant correlation between the climate indices (El Niño and Dipole indices) and the average wind speed over Northeast Brazil, mainly between February and May, period that corresponds to the four-month rainy season. Data from NCEP Reanalysis for extreme events (as the 1982-1983 El Niño events and the 1973-1974 La Niña events) suggest that, in those cases, the influence of the general circulation is so pronounced that strong events of El Niño and La Niña act as to intensify and to weaken, respectively, the winds over that region. As the smaller scale circulation associated to the sea breeze system and topographic forcing are relevant to determine the characteristics of the local wind, a mesoscale atmospheric model, the Regional Atmospheric Modeling System, (RAMS) was used to simulate the wind speed and direction from July to June of 1973-74 and of 1982-83, in order to estimate the wind variability on a seasonal time scale and the possible impacts of wind variations on the wind energy generation over Northeast Brazil
\end{abstract}

KeyWords: Climate Variability, Atmospheric Modeling, Wind Energy. 


\section{INTRODUÇÃO}

Toda uma estrutura econômica e social está atrelada ao setor energético. Especialmente em países em processo de desenvolvimento como o Brasil, a demanda por energia é cada vez maior. Na matriz energética brasileira predomina a fonte hidráulica e a geração de energia hidrelétrica esbarra nos impactos ambientais decorrentes da construção das barragens e no uso concorrente da água, fator de extrema importância no contexto do semi-árido nordestino, que enfrenta ainda hoje sérios problemas de escassez. O litoral do Nordeste brasileiro, graças à sua disposição geográfica, é favorecido com a intensidade e constância dos ventos alísios, que resulta em boas condições para a exploração desse recurso. Embora possua um ciclo anual bem definido, o vento está sujeito a variabilidade e tem uma intrínseca relação com os fenômenos meteorológicos, tornando imprescindível entender de que maneira a variabilidade climática sazonal e interanual podem influenciar a geração de energia eólica. Esse estudo visa fornecer uma base para futuros esforços na construção de um sistema de previsão de ventos e geração de energia eólica, a partir de modelos atmosféricos regionais, em curto prazo e escala sazonal, como importante ferramenta para um melhor planejamento energético e uma utilização mais eficiente dos recursos, com redução de riscos e melhor gerenciamento do sistema de geração.

As condições atmosféricas sobre a bacia do Atlântico Tropical e o comportamento do oceano influenciam fortemente a variabilidade climática sobre a região Nordeste do Brasil (Hastenrath, 1990; Rao et al., 1993; Alves, 2002). Assim como, as condições oceânicas influenciam o tempo e clima no Nordeste, também a configuração da TSM no Pacífico equatorial apresenta relação com alterações na circulação atmosférica sobre o Nordeste. (Alexander e Scott, 2002). O El Niño Oscilação Sul (ENOS) é um fenômeno de interação oceano-atmosfera que está associado ao comportamento anômalo da TSM e dos ventos alísios no Pacífico Equatorial, e, isoladamente, é o que mais contribui para a variabilidade climática e uma escala global (Zebiak, 1993).

Para fins de geração de energia eólica, as variações na velocidade e direção do vento, a densidade do ar, a topografia e rugosidade do terreno precisam ser consideradas. $\mathrm{O}$ vento utilizado para geração de energia é aquele próximo à superfície terrestre, que consequentemente está associado localmente à circulação de mesoescala, como sistemas de brisa marítima e terrestre ou vale-montanha e a forçantes topográficas.

A relação entre a potência disponível no vento e a área do rotor é dada pela densidade de Potência $\left(\mathrm{em} \mathrm{W} / \mathrm{m}^{2}\right)$ :

$$
D_{p}=\frac{P_{d i s}}{A}=\frac{1}{2} \rho v^{3}
$$

A energia total disponível no vento não pode ser extraída por um aerogerador (Hennessey, 1977), de forma que a potência máxima real que pode ser obtida é aquela obtida quando o vento deixa as pás do rotor com um terço da sua velocidade original, ou velocidade nominal. Nesse caso, o aproveitamento máximo da potência eólica disponível fica em torno de 59\% (Carvalho, 2003). Esse valor máximo obtido é chamado de Potência de Betz e é dado pela equação:

$$
P_{\text {betz }}=0,5 \rho A v^{3} \frac{16}{27}
$$

Através da Equação 1, é possível observar que a energia gerada pelo vento tem uma relação cúbica com a velocidade do vento.

\section{MATERIAL E MÉTODOS}

Com o propósito de verificar como alterações nas condições de TSM na bacia do Pacífico e Atlântico equatoriais podem influenciar a circulação atmosférica em menor escala, o Regional Atmospheric Modeling System - RAMS (Pielke et al. 1992; Cotton et al. 2003) foi utilizado para a simulação das condições de vento sobre o Nordeste do Brasil, em dois períodos distintos: julho a junho de 1973/74 e julho a junho de 1982/83. Respectivamente, estes anos correspondem a uma configuração forte de La Niña no Pacífico, acompanhada de um dipolo negativo forte no Atlântico e a uma configuração de El Niño forte, acompanhada de um dipolo positivo forte. Com o intuito de averiguar como eventos extremos, tais como os ocorridos em 1973-74 e 1982-83, alterariam o comportamento do vento sobre o nordeste brasileiro e quais poderiam ser os seus efeitos sobre a geração de energia eólica, os autores se utilizaram de dois cenários em que ocorreriam condições idênticas às encontradas nos eventos simulados com o RAMS. Uma localidade específica é considerada para ilustrar como os dados obtidos com o modelo regional poderiam ser utilizados para fins de previsão de geração de energia. Como a geração final depende também da turbina eólica utilizada, tomou-se como referência uma turbina com localização e características técnicas das turbinas que são utilizadas no Parque Eólico do Mucuripe ( $3^{\circ} 42^{\prime} 7.51^{\prime \prime} \mathrm{S}$ / 38 28'27,10" O), localizado em Fortaleza-CE. Os resultados do modelo foram interpolados para este ponto, para servirem de entrada ao WAsP como se fossem os dados observados no local. A simulação foi feita com duas grades aninhadas, a maior sobre o Nordeste, com $60 \mathrm{~km}$, e a menor com $40 \mathrm{~km}$, sobre o estado do Ceará, utilizada na tentativa de identificar com uma resolução maior o vento associado à topografia do estado do Ceará. Os esquemas de parametrização utilizados foram: Kuo para convecção, Mellor-Yamada para turbulência (Mellor e 
Yamada, 1974), Harrington para radiação (Cotton et al. 2003; Harrington e Olsson 2001) e microfísica de um momento (Walko et al. 1995). Além da simulação com o modelo de Mesoescala, foram feitas correlações entre os índices de Niño do Pacífico, para as regiões de Niño1+2, Niño3, Niño4, Niño3+4, índices de dipolo do Atlântico e as anomalias de vento (diferença entre o vento e a média dos ventos no período de 1950 a 2005), a partir de dados do NCEP. A partir dos dados de vento gerados pela simulação, foram encontrados os parâmetros da distribuição de Weibull (Equação 3). Os dados de vento obtidos com o RAMS, assim como as informações de uma turbina eólica de 1,5MW (ver curva de rendimento da turbina na Figura 1), utilizada para a estimativa de geração, foram utilizados como entrada para o Wind Atlas Analysis and Application Program (WAsP), desenvolvido pelo Risø National Laboratory (http://www.wasp.dk). Utilizando o WasP, foram determinados os parâmetros de forma e gerados os gráficos referentes à energia eólica gerada, caso ocorressem condições similares às encontradas na simulação.

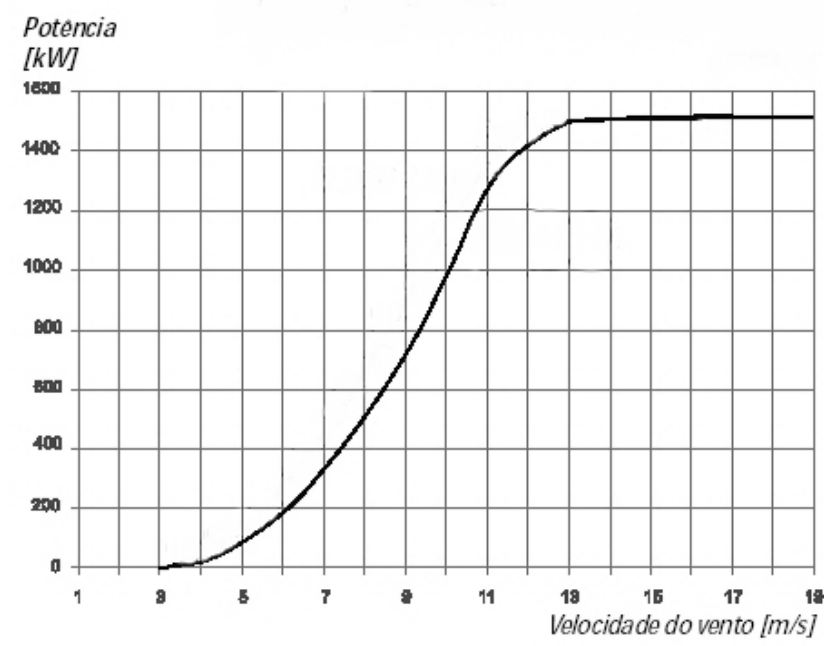

Figura 1 - Curva de rendimento de uma turbina eólica de potência $1,5 \mathrm{MW}$ e $70 \mathrm{~m}$ de altura.

$$
F_{w}=\frac{K}{A}\left(\frac{v}{A}\right)^{k-1} e^{-\left(\frac{v}{a}\right)^{k}}
$$

Nas Figuras 2 e 3, pode-se observar as condições de Niño no Pacífico, a partir do Índice Multivariado do NOAA (National Oceanic and Atmospheric Admisnistration) e as condições do Atlântico nos períodos escolhidos para a simulação.

\section{RESULTADOS}

A partir de dados do NCEP, obtivemos o vento no período escolhido para a simulação (ver Figuras 4 e 5). O ciclo anual do vento sobre o norte do nordeste do Brasil aparece bem representado nos dois gráficos. Os mínimos na intensidade do vento ocorrem durante os meses correspondentes à quadra chuvosa desta região, fevereiro a maio, e os máximos nos meses de agosto a outubro. Diferenças que podem ser consideradas significativas são encontradas entre os dois eventos: em 198383 os menores valores estão em torno de $7 \mathrm{~m} / \mathrm{s}$, enquanto em 1973/74 os menores valores encontrados são inferiores a 4m/s.

Após análise das informações de modelo Global, foram feitas correlações entre as anomalias de vento com os índices de Niño do Pacífico e Dipolo do Atlântico de 1950 a 2005, sem defasagem e com defasagem de dois meses, com o objetivo de averiguar se há defasagem na resposta do vento à influência das variações da Temperatura da Superfície do Mar (TSM) no Pacífico e o padrão de Dipolo no Atlântico. As correlações mais significativas foram encontradas no primeiro semestre, nos trimestres de Fevereiro a Abril, Maio a Julho, Abril a Junho e de Março a Maio, tanto nas correlações com os índices de Niño, como nas correlações com o Dipolo. As correlações diretas, sem defasagem, entre vento e Dipolo do Atlântico mostraram-se maiores que as correlações diretas entre vento e índices de Niño. Quando feitas com defasagem de dois meses, os índices de Niño3 e Nino 3+4 apresentaram correlações melhores do que

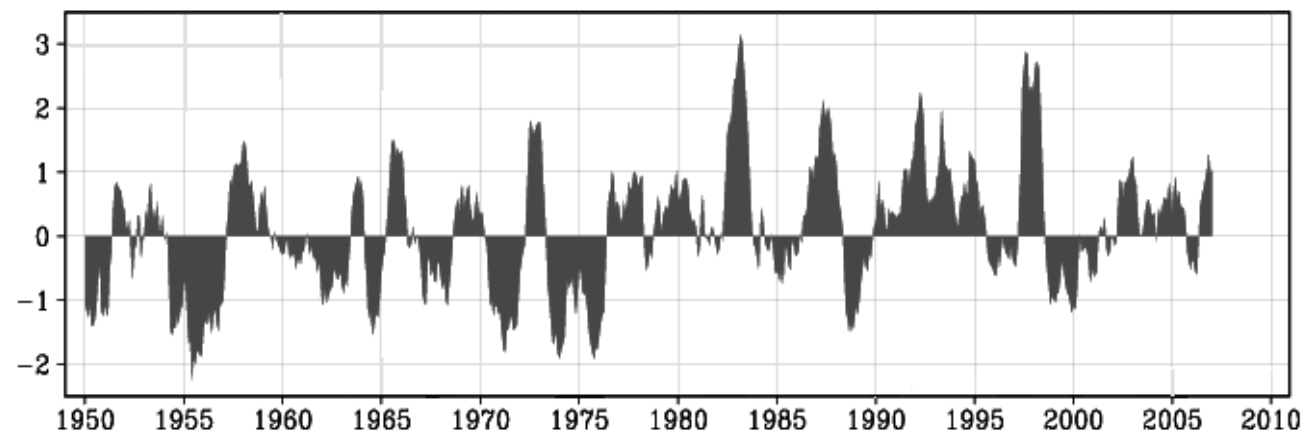

Figura 2 - Índice multivariado de El Nino Oscilação Sul. Os períodos negativos indicam a fase fria (La Niña), e os períodos positivos, as fases quentes (El Niño). Fonte: www.cdc.noaa.gov 
o Dipolo do Atlântico, caracterizando um melhor preditor, para as condições de vento sobre o Nordeste nos meses de fevereiro a maio. O teste $t$ de significância aponta para correlações com significância da ordem de 99\%. Segundo SPIEGEL, para amostras superiores a trinta anos, uma correlação de 0,30 pode ser considerada alta.

Nas Tabelas 1 e 2, os valores de correlação entre o vento e os índices de Dipolo e Nino com defasagem e sem defasagem de dois meses, respectivamente.
Os resultados da grade de maior resolução, utilizada na simulação dos eventos de El Niño (82/83) e La Niña (73/74), podem ser vistos nas Figuras 6 a 8. Os mapas mostram a diferença de velocidade (em $\mathrm{m} / \mathrm{s}$ ) e direção do vento entre os eventos supracitados. Observam-se as diferenças mais significativas no regime de ventos no quadrimestre de Fevereiro a Maio, onde é possível observar diferenças de no mínimo $0,5 \mathrm{~m} / \mathrm{s}$ em fevereiro e no máximo $5 \mathrm{~m} / \mathrm{s}$ em abril. Abril aparece como o mês mais contrastante. O vento em abril de 1974,

Tabela 1 - Valores de correlações mais significativas entre o vento e os índices de Niño e de dipolo.

\begin{tabular}{|c|ccccc|}
\hline Trimestre & Dipolo & Niño 1+2 & Niño 3 & Niño 4 & Niño 3+4 \\
\hline Fevereiro-Março-Abril & 0,4755 & 0,4432 & 0,5227 & 0,4349 & 0,4995 \\
\hline & & & & & \\
Março-Abril-Maio & 0,5626 & 0,482 & 0,5886 & 0,4546 & 0,5501 \\
\hline & & & & & \\
Abril-Maio-Junho & 0,573 & 0,4538 & 0,5666 & 0,4749 & 0,5465 \\
\hline & & & & & \\
Maio-Junho-Julho & 0,4524 & 0,4227 & 0,5273 & 0,5071 & 0,528 \\
\hline
\end{tabular}

Tabela 2 - Valores das correlações mais significativas entre os índices de Niño e de dipolo, e o vento com defasagem de dois meses.

\begin{tabular}{|c|ccccc|}
\hline Trimestres & Dipolo & Niño 1+2 & Niño 3 & Niño 4 & Niño 3+4 \\
\hline JFM x MAM & 0,4525 & 0,4326 & 0,4326 & 0,4155 & 0,3933 \\
\hline FMA x AMJ & 0,5311 & 0,4747 & 0,4747 & 0,4511 & 0,4456 \\
\hline MAM x MJJ & 0,5921 & 0,4594 & 0,4594 & 0,4329 & 0,4797 \\
\hline AMJ x JJA & 0,3787 & 0,193 & 0,193 & 0,1608 & 0,3935 \\
\hline
\end{tabular}
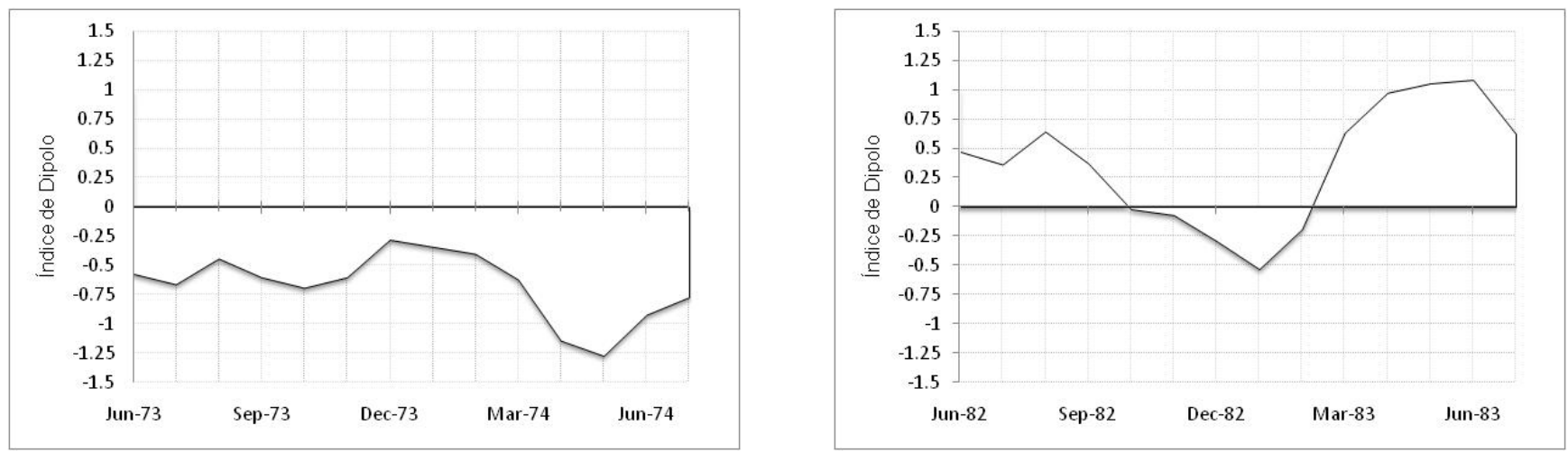

Figura 3 - Índices de dipolo do Atlântico. À esquerda, julho a junho de 1973/74 e à direita o mesmo período em $1982 / 83$. 
segundo o modelo, estava predominantemente de nordeste. Ventos de nordeste como nesse caso favorecem o deslocamento da Zona de Convergência Intertropical (ZCIT) mais ao sul. No nordeste brasileiro, o deslocamento da ZCIT mais a sul é o principal responsável pelas chuvas no período da quadra chuvosa. Este resultado é coerente, pois a quadra chuvosa de 1974 foi marcada por chuvas com um desvio de até $100 \%$ acima da média histórica, segundo dados da Fundação Cearense de

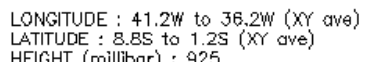
LATITUDE : 8.85 to $1.2 \mathrm{~S}$ ( $\mathrm{XY}$ ave

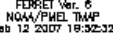

DATA SET: Dados NCEP

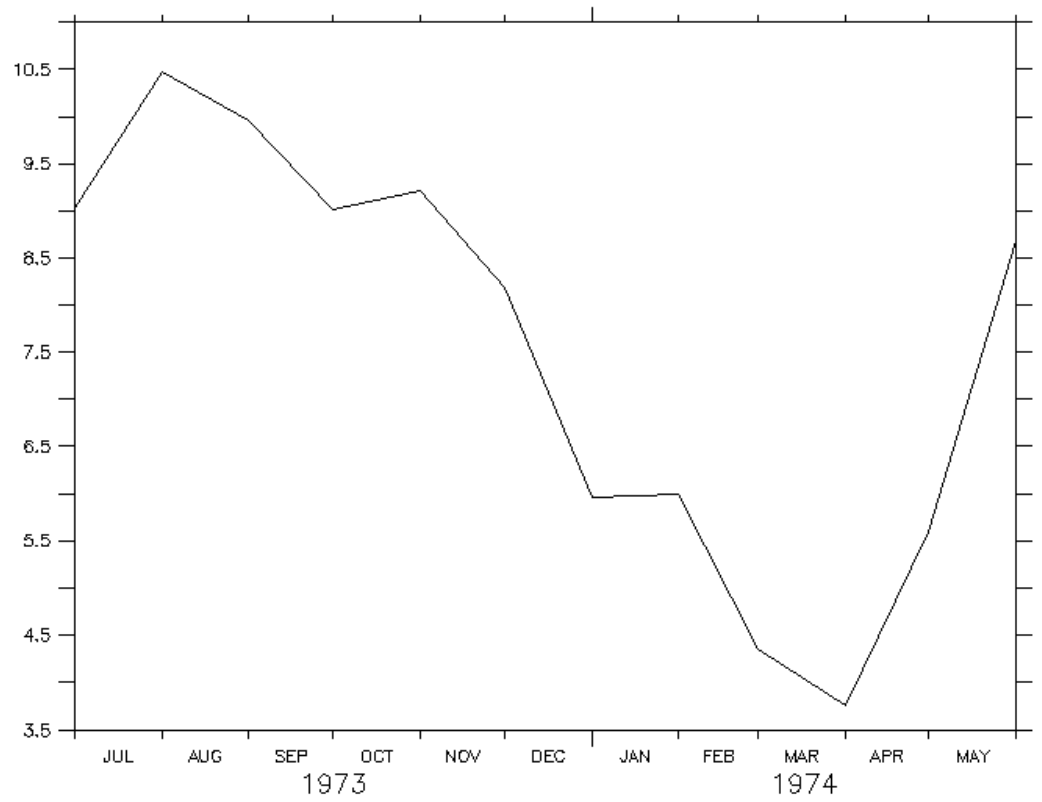

Figura 4 - Média mensal do vento (em m/s) a 925hPa sobre o Nordeste brasileiro com destaque para o período de 1973/74

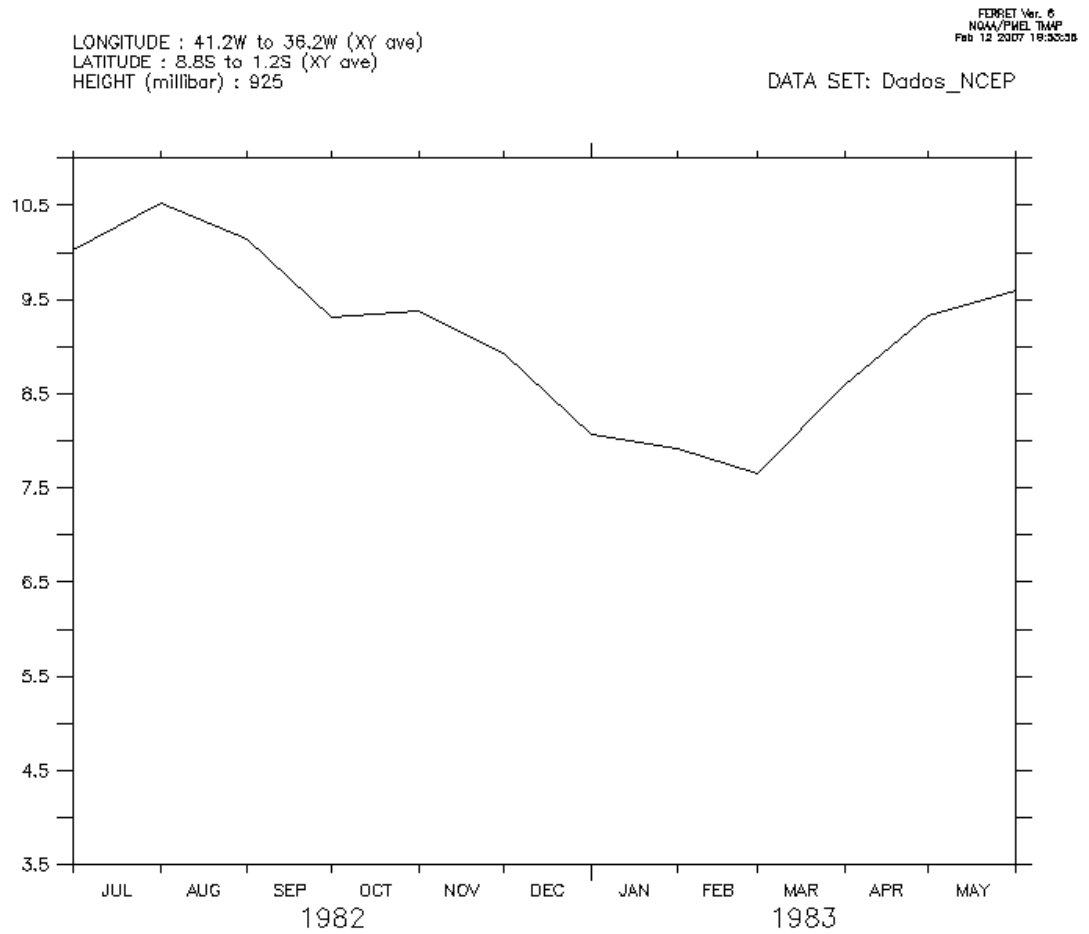

Figura 5 - Média mensal do vento (em m/s) a 925hPa sobre o Nordeste Brasileiro com destaque para o período de 1982/83. 
Meteorologia e Recursos Hídricos (FUNCEME). Já em abril de 1983 o comportamento do vento em baixos níveis é bastante coerente com o que acontece em eventos de El Niño combinados com dipolo positivo, que geralmente são associados a períodos mais secos sobre o Nordeste. O vento em abril de 1983 foi
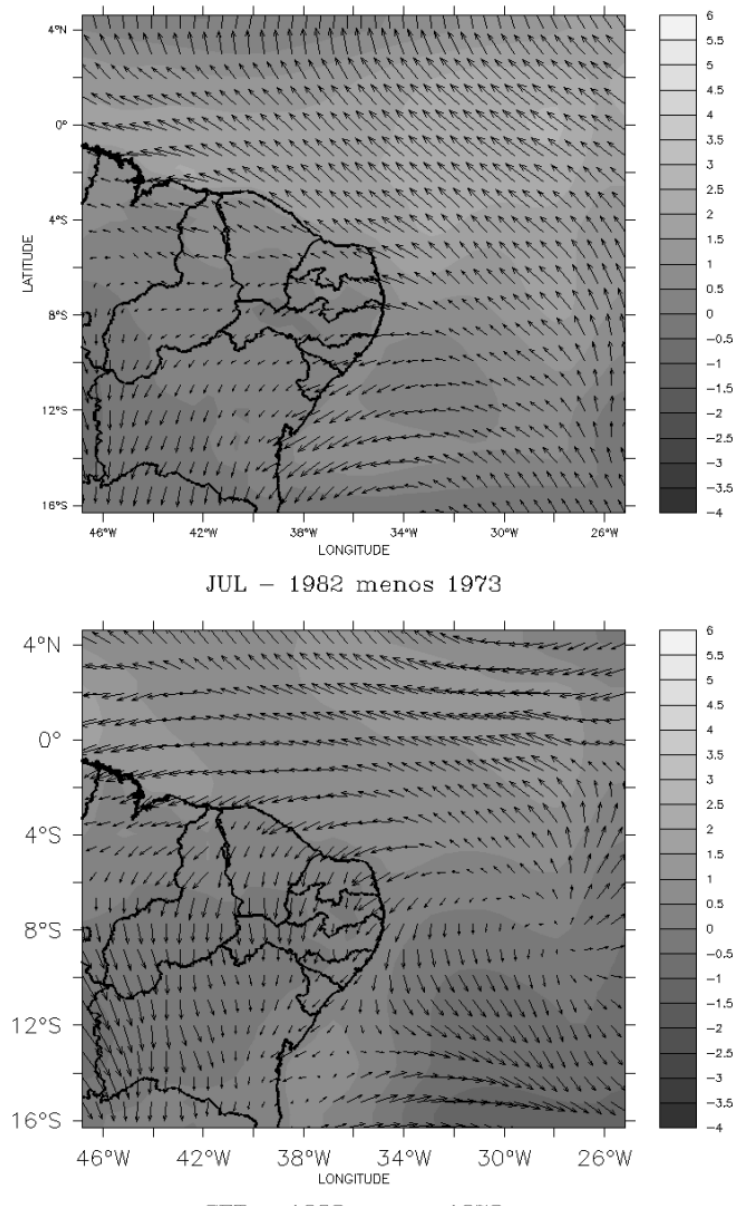

SET - 1982 menos 1973

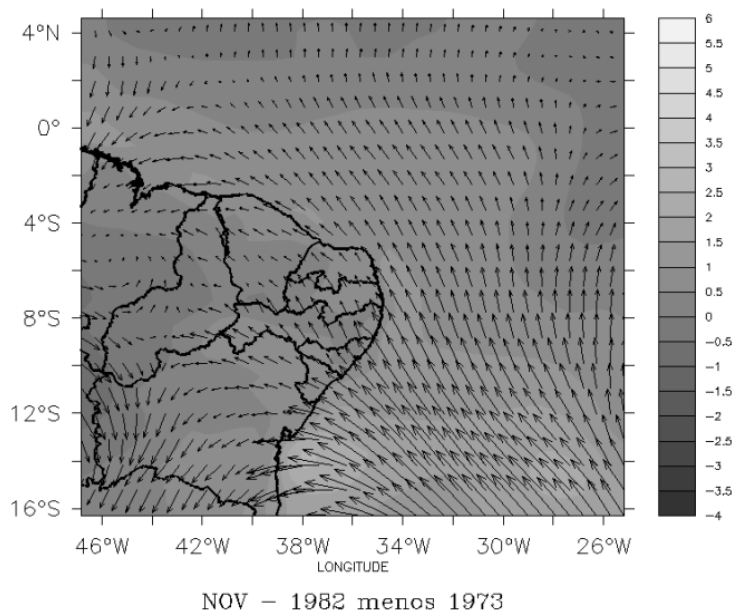

representado pelo modelo como sendo predominantemente de sudeste e bem mais intenso do que em abril de 1974. Nesse período, portanto, a Zona de Convergência Intertropical (ZCIT) não teve condições favoráveis ao seu deslocamento e permanência mais ao sul.
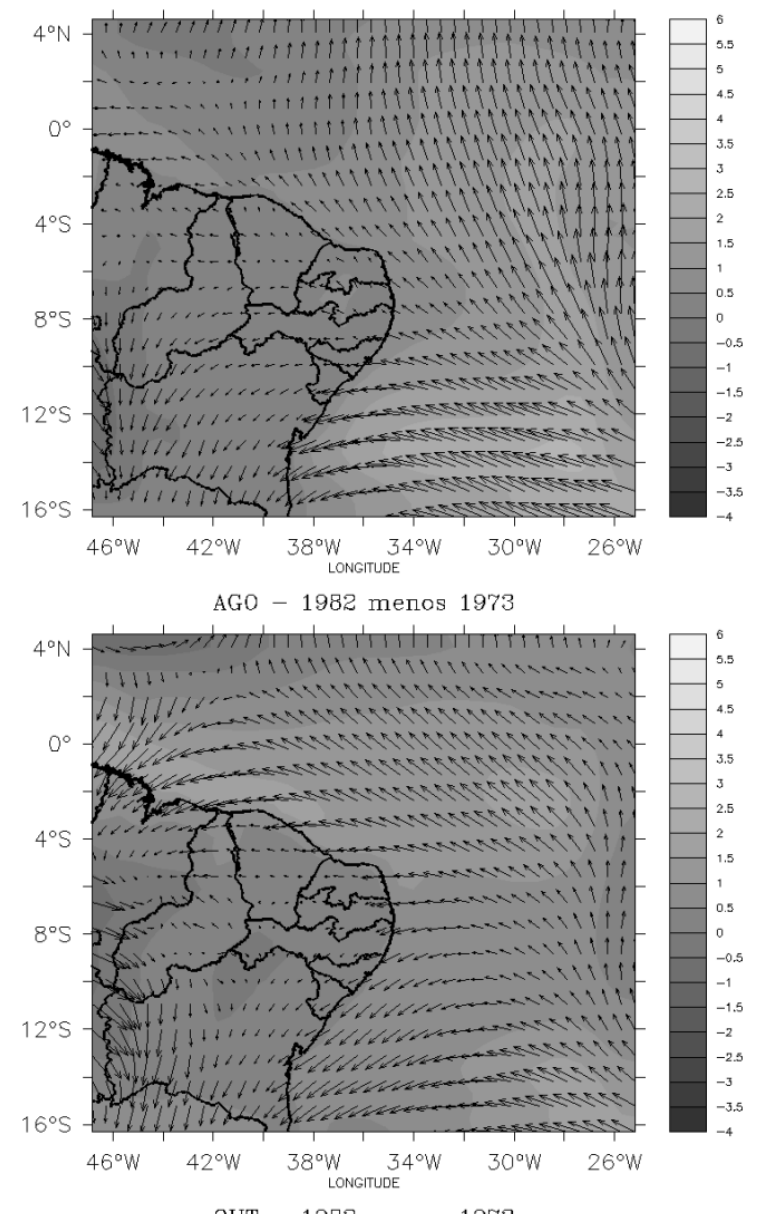

OUT - 1982 menos 1973

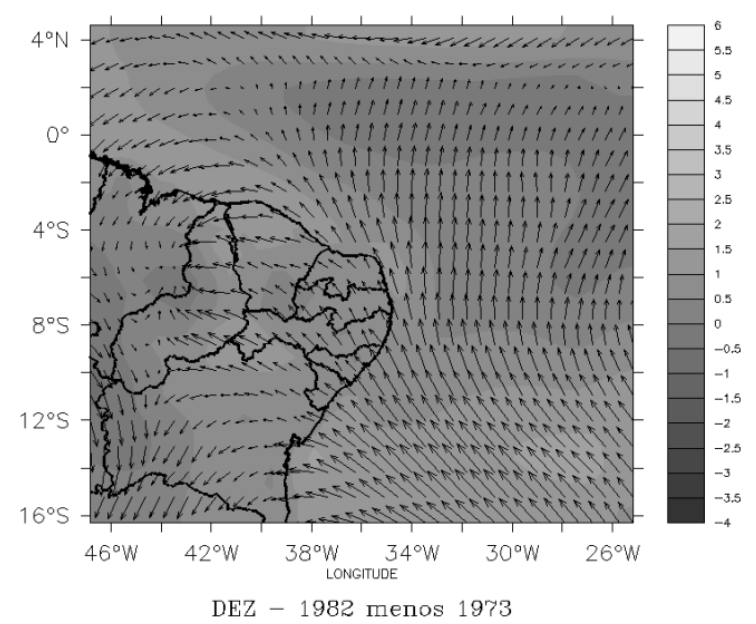

Figura 6 - Resultados do modelo para a grade maior - diferença de velocidade e direção do vento entre os eventos de 1982 e 1973 nos meses de julho a dezembro. Valores positivos indicam ventos mais pronunciados no evento de 1982. 
Nos meses representados nas Figuras 6 e 8, as diferenças entre os dois eventos são bem menores do que as diferenças encontradas nas Figuras 7 e 9, evidenciando que as alterações mais importantes no comportamento do vento ocorrem em decorrência da influência de sistemas de grande escala como

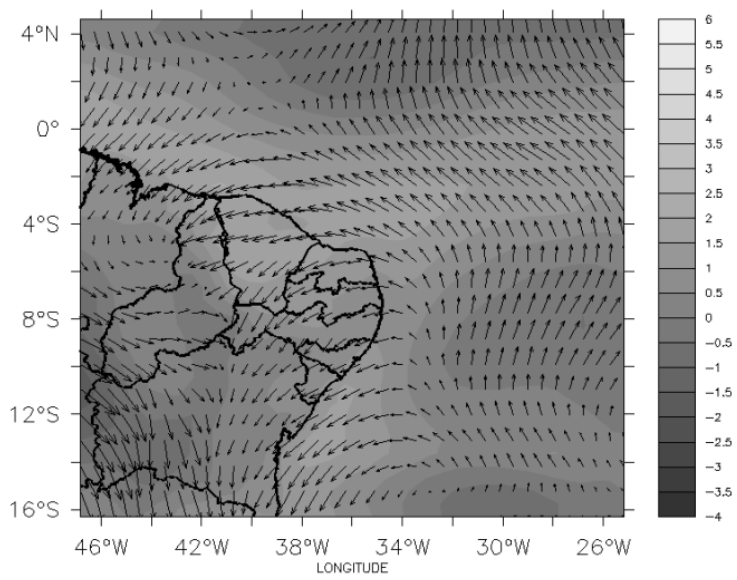

JAN - 1983 menos 1974

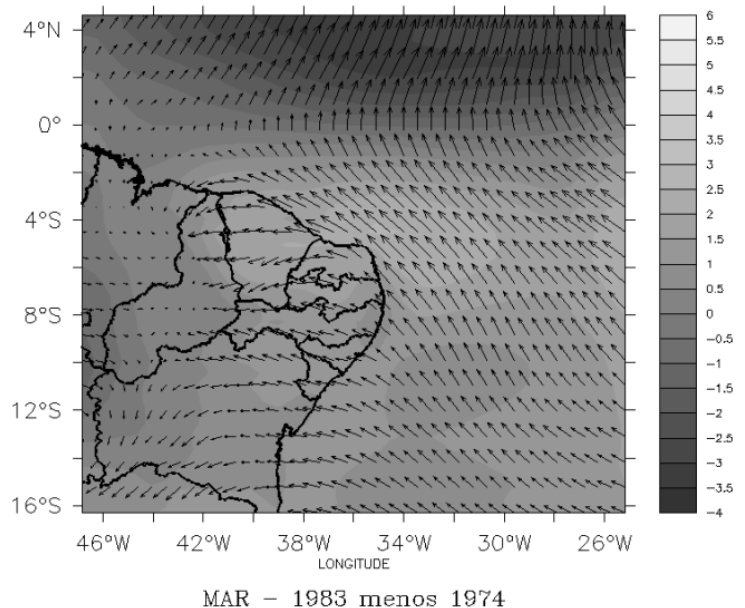

MAR - 1983 menos 1974

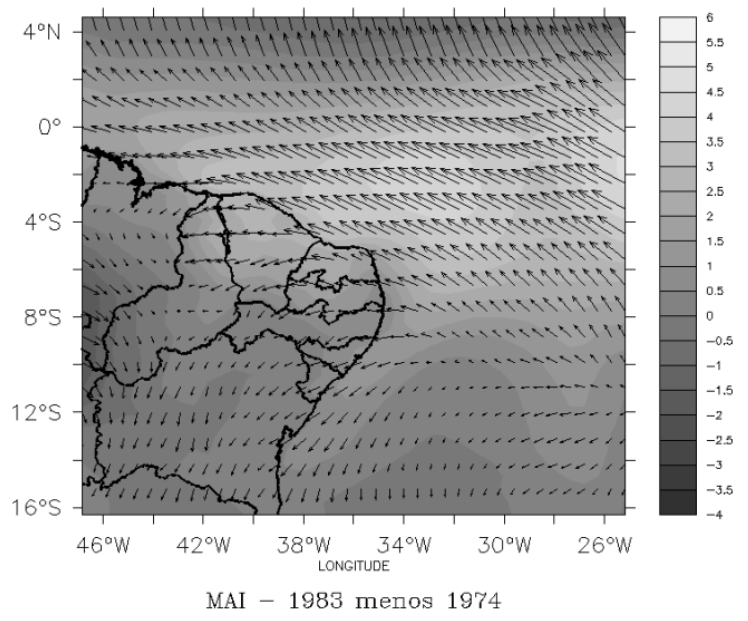

a ZCIT e das anomalias de TSM no Pacífico e Atlântico. Nos meses de agosto e setembro de 1982, o Atlântico se encontrava com um dipolo positivo passando nos meses seguintes a um dipolo negativo bem configurado, que permaneceu até fevereiro de 1983. No entanto, o vento mostrou-se mais intenso mesmo
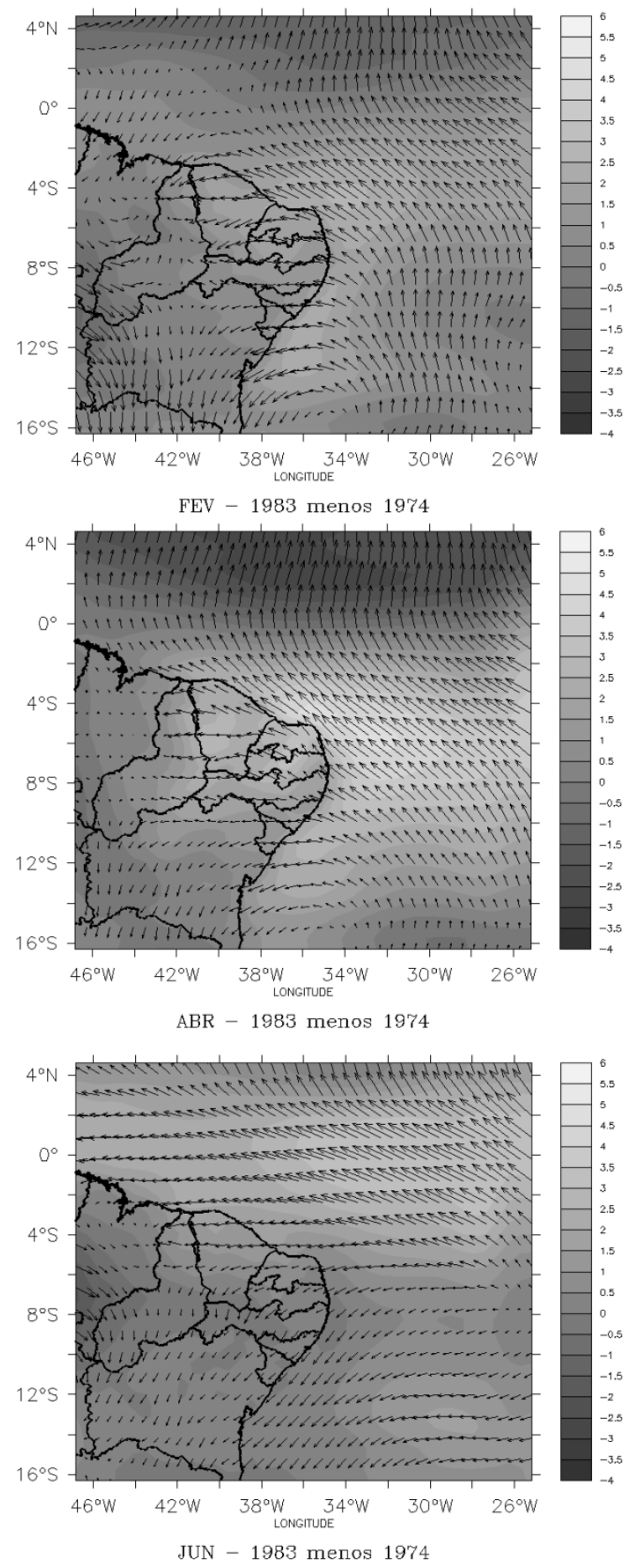

Figura 7 - Resultado do modelo para a grade maior - diferença de velocidade e direção do vento entre os eventos de 1983 e 1974 nos meses de janeiro a junho. Valores positivos indicam ventos mais pronunciados no evento de 1983. 
nos meses correspondentes ao dipolo negativo em 1982/83 em relação ao mesmo período de 1973/74, indicando que as condições do Pacífico parecem estar mais relacionadas às variações na velocidade do vento nesses meses, do que às condições de dipolo do Atlântico. É importante observar

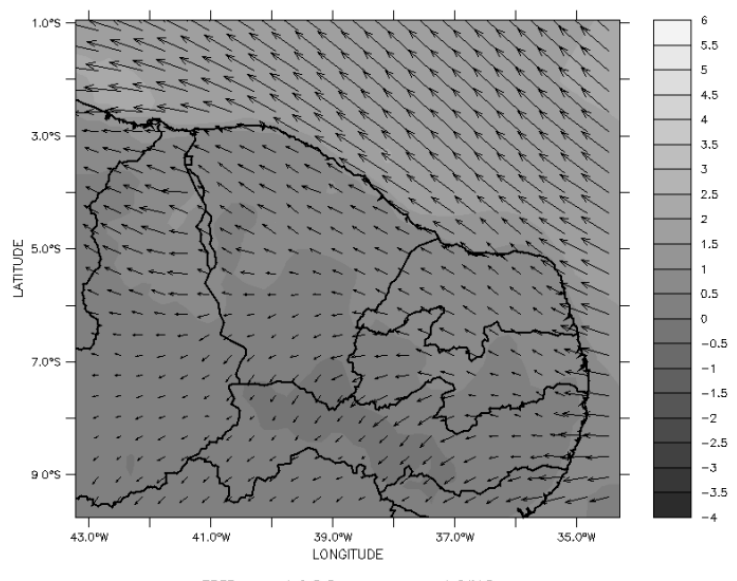

JUL - 1982 menos 1973
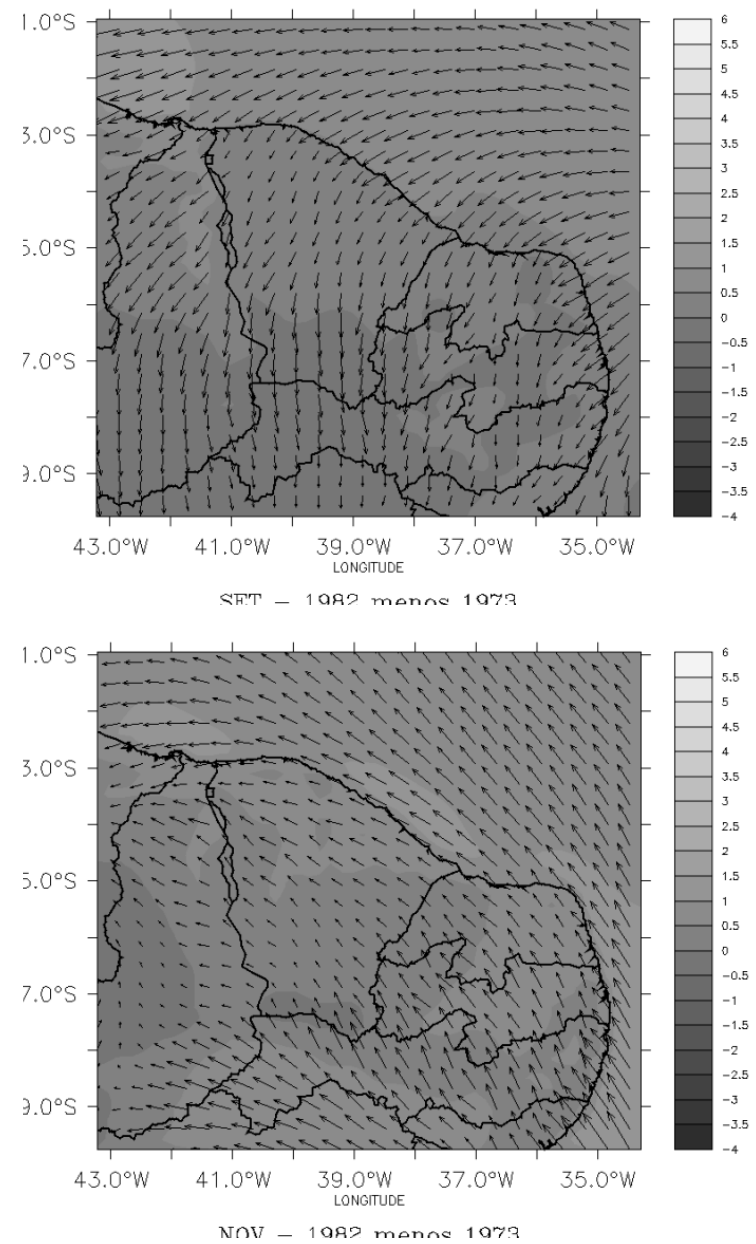

também que não só o deslocamento da ZCIT está associado às variações no regime dos ventos, já que nesses meses a ZCIT não se encontra sobre a região nordeste do Brasil.

As variações do vento encontradas com a simulação entre os dois eventos são bastante significativas, especialmente para a
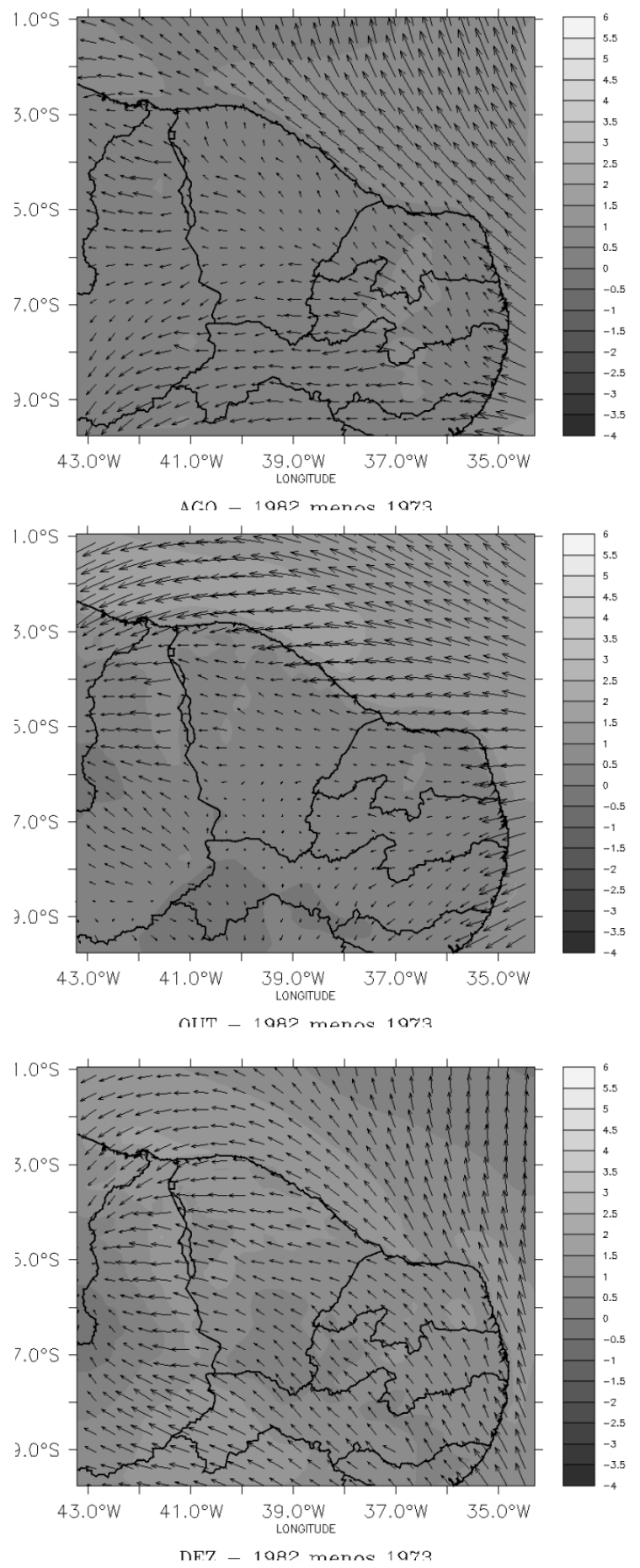

Figura 8 - Resultados do modelo para a grade menor - diferença de velocidade e direção do vento entre os eventos de 1982 e 1973 nos meses de julho a dezembro. 
geração de energia eólica, já que a energia final extraída do vento varia com o cubo da velocidade do vento (Carvalho, 2003).

Uma estimativa dos efeitos dessa variabilidade na intensidade e direção do vento na geração de energia eólica é feita a seguir. Nas distribuições de Weibull apresentadas nas
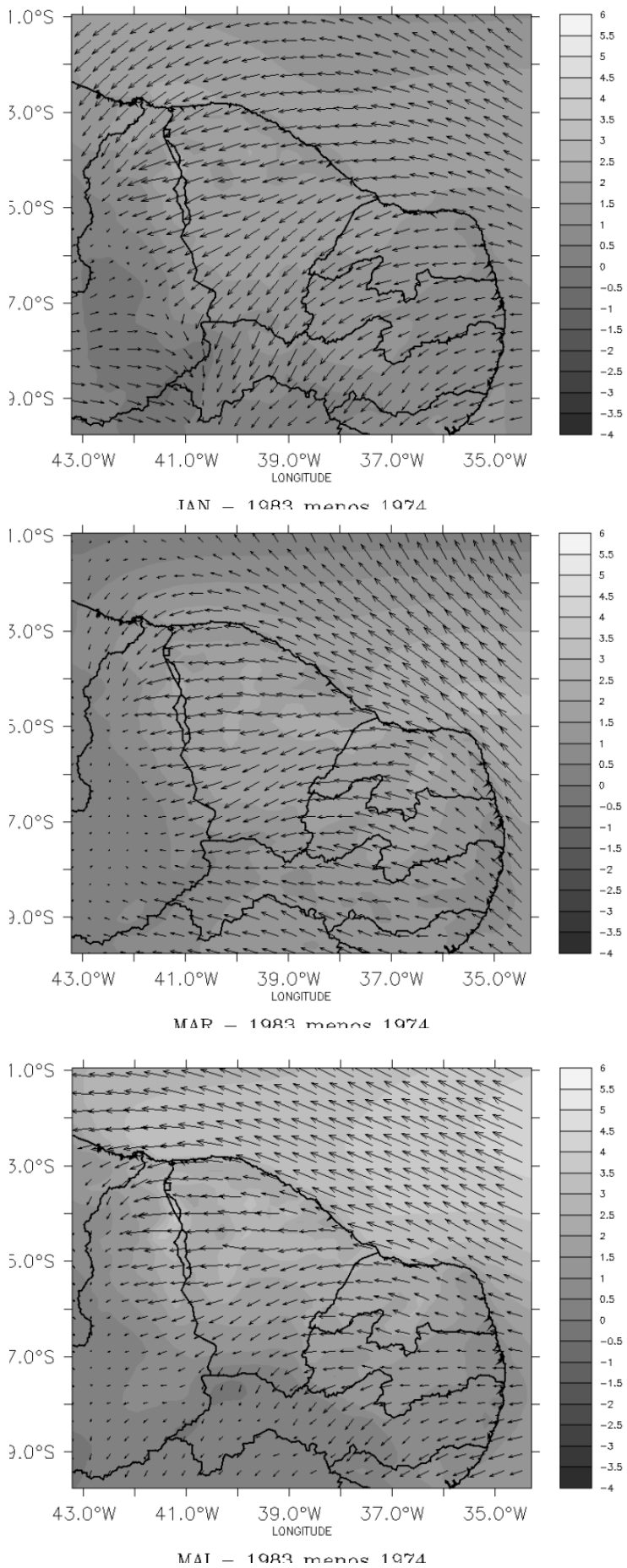

Figuras 10 e 11, temos a distribuição estatística do vento ao longo dos meses em questão. $\mathrm{O}$ eixo das abscissas representa a velocidade do vento e o eixo das ordenadas representa a freqüência (em porcentagem) da ocorrência de vento com um determinado valor x. Além da distribuição de freqüências, as
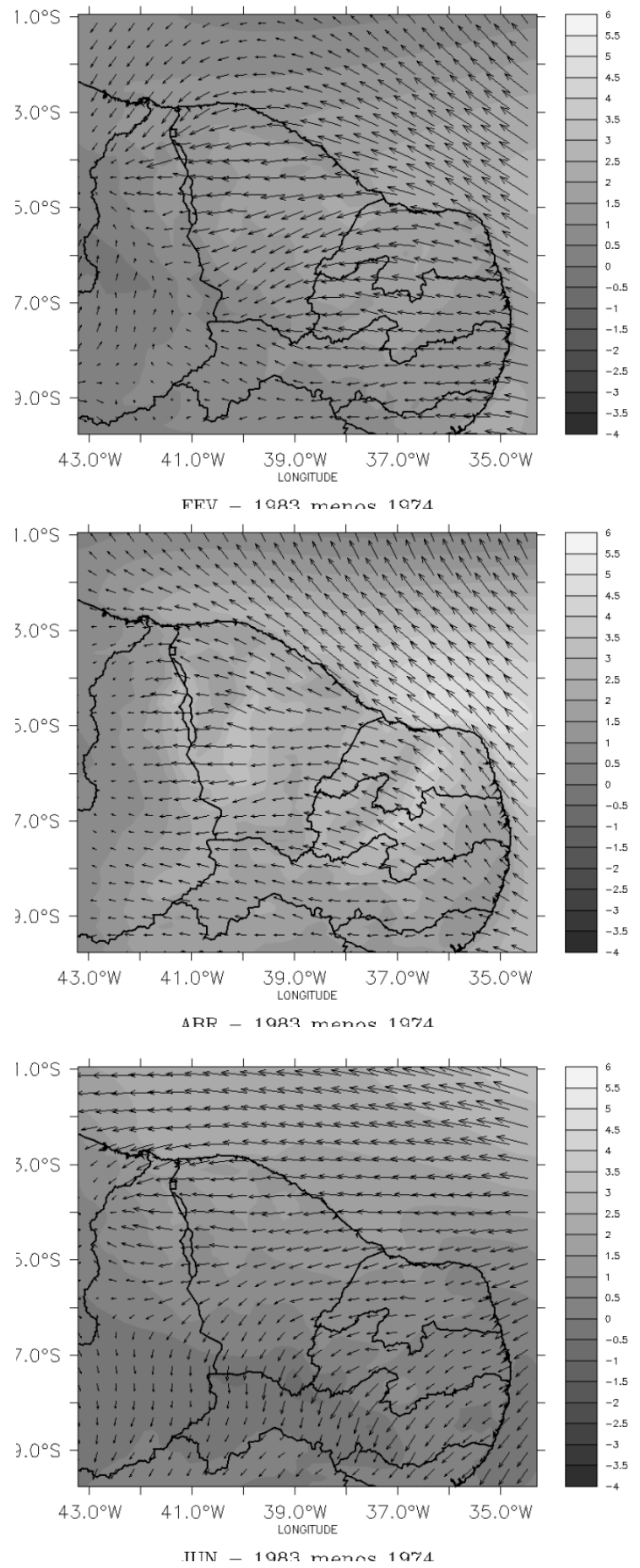

Figura 9 - Resultado do modelo para a grade menor - diferença de velocidade e direção do vento entre os eventos de 1983 e 1974 nos meses de janeiro a junho. 
figuras abaixo contam também com a representação da direção do vento através da rosa-dos-ventos.

Os parâmetros relacionados nos histogramas são: o parâmetro de forma $(\mathrm{k})$, valor adimensional que define a inclinação da curva de distribuição, e o fator de escala (A) que está relacionado à velocidade média do vento. U indica a velocidade média do vento dentro da distribuição e $\mathrm{P}$ dá o valor da densidade de potência em $\mathrm{W} / \mathrm{m}^{2}$.

A variação desses parâmetros permite avaliar a variabilidade do vento. O fator de forma, por

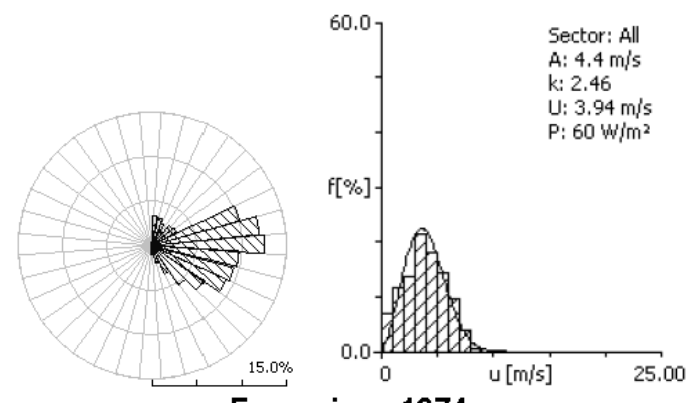

Fevereiro - 1974

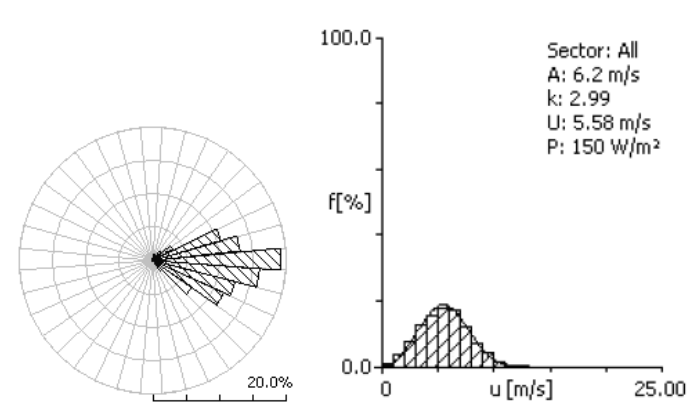

Fevereiro - 1983
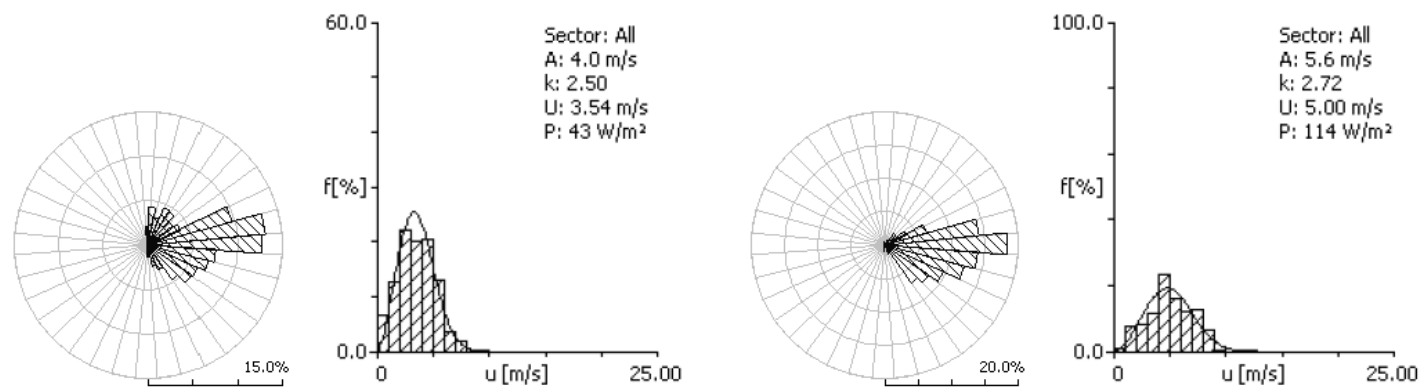

Março - 1974

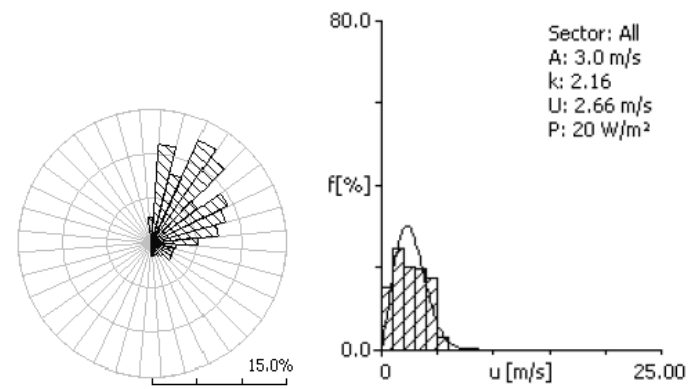

Abril - 1974

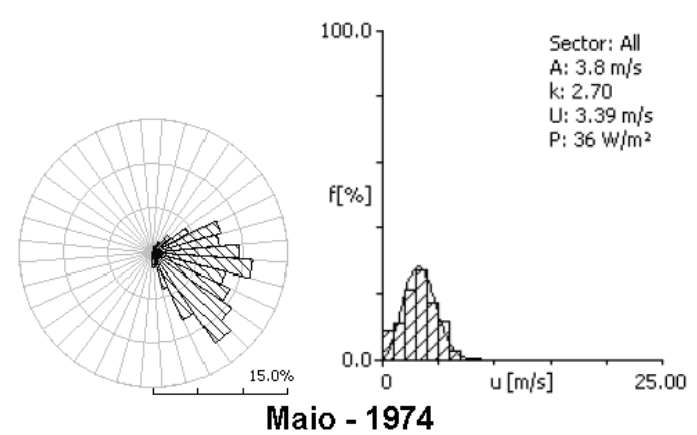

Março - 1983

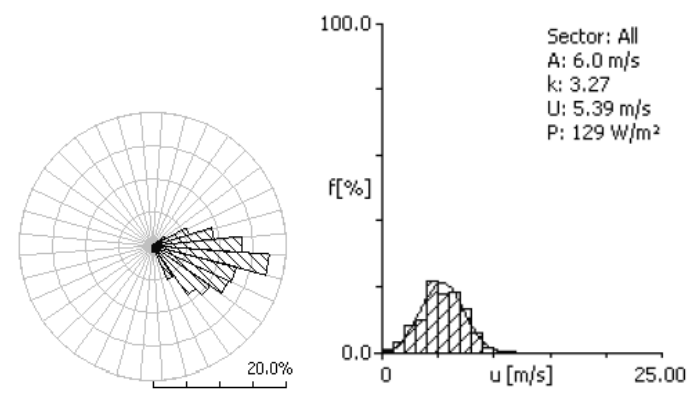

Abril - 1983

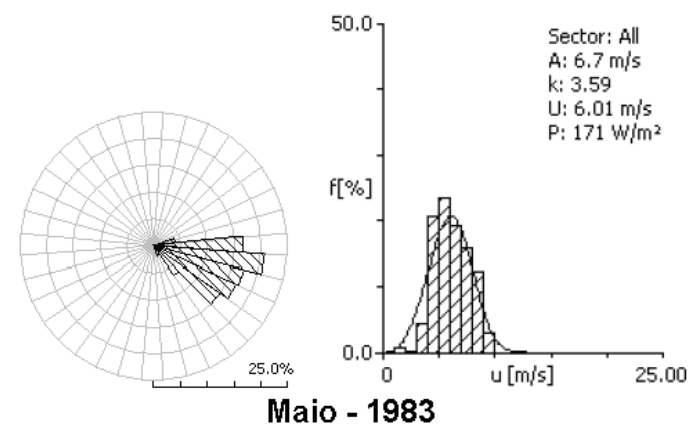

Figura 10 - Distribuição de direção e intensidade dos ventos para os meses de fevereiro a maio no local correspondente ao Parque Eólico do Mucuripe, em Fortaleza-CE. À esquerda condições similares ao ano de 1974 e à direita condições similares ao ano de 1983. 
exemplo, é inversamente proporcional à variação da velocidade do vento, e quanto maior o fator de escala, mais larga será a distribuição (no caso de k constante) indicando menor variação da velocidade do vento.
No caso de La Niña de 1974, em pouco mais de $20 \%$ do mês, a velocidade do vento tem valores máximos em torno de $3,94 \mathrm{~m} / \mathrm{s}$ e ventos soprando predominantemente de leste e de nordeste. Em comparação, no mês de fevereiro de 1983, os
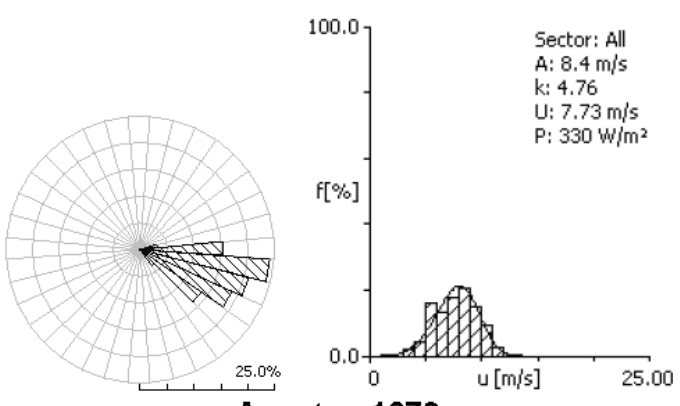

Agosto - 1973
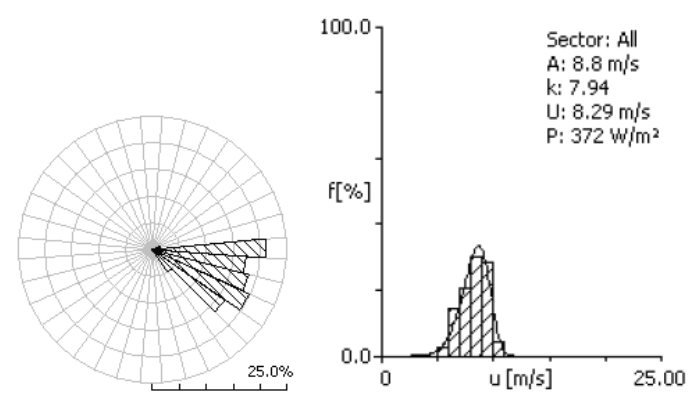

Agosto - 1982
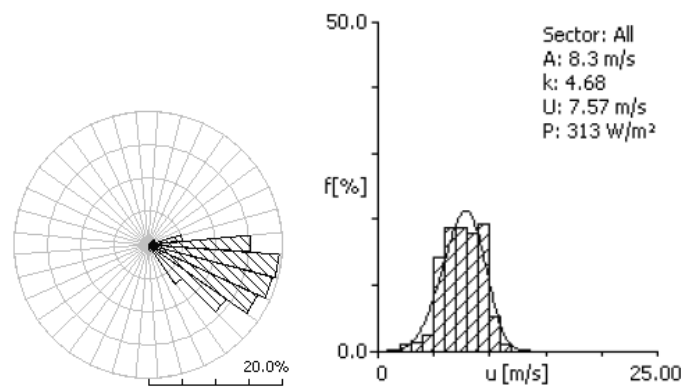

Setembro - 1973

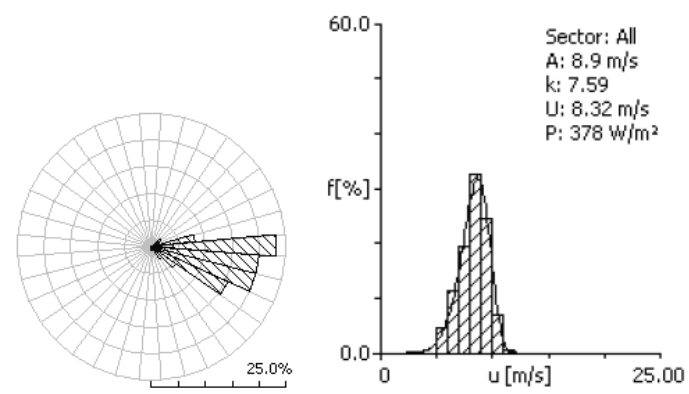

Setembro - 1982
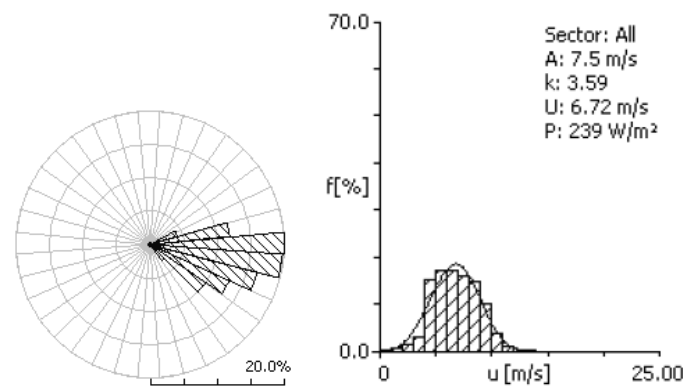

Outubro - 1973
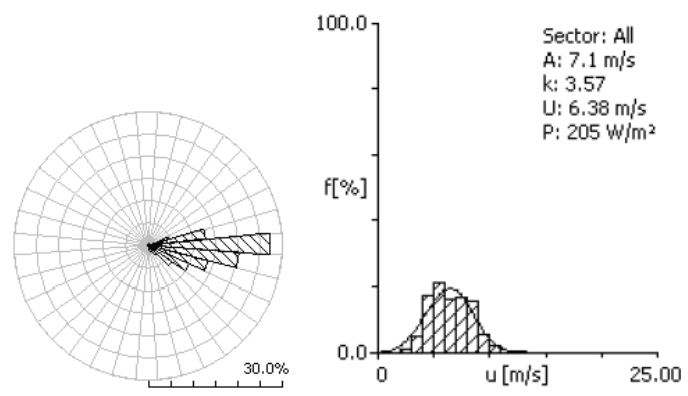

Novembro - 1973
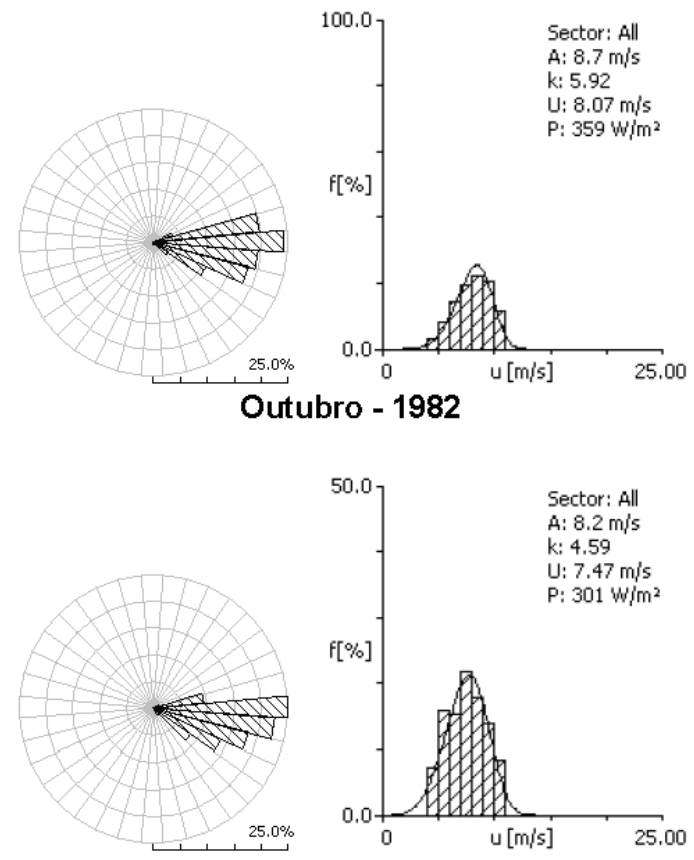

Outubro - 1982

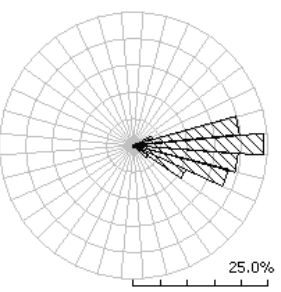

Novembro - 1982

Figura 11 - Distribuição de direção e intensidade dos ventos para os meses de agosto a novembro no local correspondente ao Parque Eólico do Mucuripe, em Fortaleza-CE. À esquerda condições similares ao ano de 1973 e à direita condições similares ao ano de 1982. 
ventos mais intensos (em torno de $5,5 \mathrm{~m} / \mathrm{s}$ ) ocorrem em $25 \%$ do mê vindos de sudeste e leste.

Em março, percebe-se que no episódio de La Niña os ventos aparecem mais de nordeste que no episódio de 1983, e a velocidade do vento é mais constante em 1974, mas apresenta valores menores, enquanto em 1983 os valores são maiores, chegando a quase $10,0 \mathrm{~m} / \mathrm{s}$, mas a freqüência de intensidade do vento varia bastante. A densidade de potência $(\mathrm{P})$ varia significativamente entre os dois episódios, já que a potência eólica disponível varia com o cubo da velocidade.

O período de fevereiro a maio de 1974 se apresenta como o pior cenário para a geração de energia, especialmente o mês de abril, que apresenta ventos fracos predominantemente de nordeste e leste. Nesse caso a densidade de potência seria de apenas $20 \mathrm{~W} / \mathrm{m}^{2}$, enquanto, no mês de abril de 1983, a densidade de potência chega a $129,0 \mathrm{~W} / \mathrm{m}^{2}$. Considerando que as turbinas, em geral, necessitam de ventos com velocidade de no mínimo $3,0 \mathrm{~m} / \mathrm{s}$ para dar início à produção de eletricidade, é possível que em condições similares às apresentadas em abril de 1974, o parque permaneça com as turbinas inoperantes durante alguns dias ou horas.

A freqüência maior é de ventos em torno de $3,39 \mathrm{~m} / \mathrm{s}$ em maio do ano de La Niña e a densidade de potência é de $36 \mathrm{~W} / \mathrm{m}^{2}$, enquanto em maio de El Niño a densidade de potência chega a $171 \mathrm{~W} / \mathrm{m}^{2}$ e predominam ventos em torno de $6,01 \mathrm{~m} / \mathrm{s}$. Neste último os ventos já não sopram de nordeste como no ano de La Niña, isso marca a migração precoce da ZCIT para latitudes menores ou para o hemisfério Norte.

Para o quadrimestre de agosto a novembro, a estimativa de produção de energia é bem melhor que no quadrimestre analisado anteriormente, mas ainda assim, o episódio de 1973/74, que nesses meses encontrava-se em desenvolvimento, compromete um pouco o potencial eólico sobre o Nordeste.
O primeiro gráfico da Figura 10 nos dá as condições de geração para o mês de agosto. A direção do vento não varia muito entre os dois períodos predominando ventos de sudeste leste. Esse padrão se repete nos meses seguintes (setembro a novembro), mas a velocidade média do vento e a densidade de potência obtida apresentam uma variação interessante: da predominância de ventos em torno de $7,73 \mathrm{~m} / \mathrm{s}$ e densidade de potência de $330 \mathrm{~W} / \mathrm{m}^{2}$ em agosto de 1973 , a ventos em torno de $8,29 \mathrm{~m} / \mathrm{s}$ e densidade de potência de $372 \mathrm{~W} / \mathrm{m}^{2}$ em agosto de 1982 .

O mês de setembro é o que apresenta melhores condições para a geração de energia eólica, mesmo em condições relativamente mais desfavoráveis. Sua densidade de potência é de $313 \mathrm{~W} / \mathrm{m}^{2}$ em 1973 e $378,0 \mathrm{~W} / \mathrm{m}^{2}$ em 1982, sendo esse valor o maior encontrado em todo o período analisado

Nos meses de outubro e novembro, a densidade de potência chega a variar em média $100,0 \mathrm{~W} / \mathrm{m}^{2}$ do evento de $\mathrm{La}$ Niña para o evento de El Niño, em função do incremento de pouco mais de 1m/s na velocidade do vento em 1982 em relação a 1973 .

Na Tabela 3, observa-se a estimativa de geração mensal de energia (em MWh) com uma turbina de 1,5MW de potência nominal, como descrito na metodologia.

\section{CONCLUSÕES}

O fato da energia elétrica, obtida a partir de aerogeradores ser proporcional à velocidade do vento ao cubo, torna a geração de eletricidade particularmente sensível às variações da velocidade do vento, de forma que pequenas alterações na velocidade do vento podem acarretar variações significativas na produção final de energia. Os resultados aqui apresentados

Tabela 3 - Estimativa de geração mensal de energia (em MWh) a partir de um turbina hipotética de 1,5MW de potência nominal e 70m de altura, na localidade correspondente ao Parque Eólico do Mucuripe em Fortaleza-CE.

\begin{tabular}{|c|c|c|c|}
\hline Mês/ano & $\begin{array}{c}\text { Energia gerada } \\
(\mathrm{em} \text { MWh })\end{array}$ & Mês/ano & $\begin{array}{c}\text { Energia gerada } \\
(\mathrm{em} \mathrm{MWh})\end{array}$ \\
\hline $\mathrm{ago} / 73$ & 429,15 & $\mathrm{ago} / 82$ & 499,39 \\
\hline $\mathrm{set} / 73$ & 401,34 & $\mathrm{set} / 82$ & 498,98 \\
\hline $\mathrm{out} / 73$ & 315,26 & $\mathrm{out} / 82$ & 476,63 \\
\hline $\mathrm{nov} / 73$ & 259,06 & $\mathrm{nov} / 82$ & 387,69 \\
\hline $\mathrm{fev} / 74$ & 57,96 & $\mathrm{fev} / 83$ & 166,69 \\
\hline $\mathrm{mar} / 74$ & 43,86 & $\mathrm{mar} / 83$ & 138,43 \\
\hline $\mathrm{abr} / 74$ & 15,26 & $\mathrm{abr} / 83$ & 154,52 \\
\hline $\mathrm{mai} / 74$ & 32,93 & $\mathrm{mai} / 83$ & 222,86 \\
\hline
\end{tabular}


têm por intuito ilustrar uma das inúmeras possibilidades de uso do modelo atmosférico RAMS como ferramenta para alimentar um sistema de previsão de ventos, seja em curto prazo ou em escala sazonal.

Sabe-se que o clima no Nordeste brasileiro é bastante suscetível às alterações nos padrões de pressão atmosférica e TSM nas bacias dos oceanos Atlântico e Pacífico. Nesse caso, especialmente anomalias oceânico-atmosféricas ocorridas nas regiões de Niño3 e Niño 3+4 têm influência sobre o vento.

Como os eventos de dipolo e ENOS ocorreram simultaneamente nos períodos de julho de 1973/1982 a junho de 1974/1983, e não foi realizada neste trabalho uma análise mais detalhada para determinar a influência de cada um destes fenômenos separadamente, é difícil discriminar qual desses fenômenos contribui de maneira mais significativa com as alterações na velocidade do vento. Entretanto, percebe-se que no segundo semestre - quando o padrão de dipolo não é tão intenso como o encontrado nos meses da quadra chuvosa sobre o Norte do Nordeste brasileiro - que o fenômeno ENOS parece ser o que mais contribui com a variabilidade do vento.

Mesmo em condições relativamente desfavoráveis, a intensidade do vento sobre o Nordeste brasileiro mostrou-se, em geral, adequada para a geração de energia eólica. No período de agosto a novembro, parte da faixa litorânea da Bahia e de Sergipe, e litorais do Rio Grande do Norte, Ceará e Piauí, apresentaram excelentes condições de vento (figuras correspondentes à grade de $60 \mathrm{~km}$ do modelo).

Sobre o oceano Atlântico, entre o Estado do Rio Grande do Norte, parte do litorais leste e norte do estado do Ceará, e próximo ao Piauí, os valores encontrados indicam potencial off-shore elevado. Esse padrão se repete nos dois eventos, logo após o primeiro quadrimestre dos anos analisados.

Como os resultados mostrados aqui são médias mensais, os efeitos de brisa não puderam ser observados, mas os resultados da simulação foram obtidos de hora em hora e, nesse caso, o modelo RAMS também simulou bem os mecanismos de brisa.

Em suma, o modelo representou bem, mesmo sem correção estatística, as alterações no vento sobre o NEB e o estado do Ceará, em particular, em função das alterações nas condições de TSM sobre a porção equatorial dos Oceanos Pacífico e Atlântico. O modelo também representou bem o comportamento do vento diante dos padrões de circulação local associados à topografia. O fenômeno El Niño, acoplado ao padrão de dipolo positivo no Atlântico, aparece favorável à produção de energia élica em contraste com os ventos reduzidos no evento de La Niña acoplado com um dipolo negativo.

As alterações na TSM do Pacífico nas regiões de Niño3 e Niño3+4 precedem em dois meses, com uma boa correlação, alterações na velocidade do vento sobre o NEB. O vento responde de forma mais imediata às alterações na TSM do Atlântico Tropical.

\section{AGRADECIMENTOS}

Este trabalho recebeu apoio da Coordenação de Aperfeiçoamento de Pessoal de Nível Superior (CAPES), Conselho Nacional de Desenvolvimento Científico e Tecnológico (CNPQ), Fundação Cearense de Amparo à Pesquisa (FUNCAP) e Fundação Cearense de Meteorologia e Recursos Hídricos (FUNCEME).

\section{REFERÊNCIAS}

ALEXANDER, M., SCOTT, J. The influence of Air-Sea interaction in the Atlantic. Geophysical Research Letters, 14, 2002.

ALVES, J. M. B. Reanálise de índices de temperatura da superfície do mar no Atlântico e Pacífico tropicais, potenciais indicadores da qualidade da estação chuvosa do setor norte do Nordeste do Brasil. Revista brasileira de Agrometeorologia, 10, 179-187, 2002.

CARVALHO, P. Geração eólica. Imprensa universitária, 146 pp, 2003.

COTTON, W.R., PIELKE, R.A., WALKO, R.L., LISTON, G.E., TREMBACK, C.J., JIANG, H., MCANNELLY, R.L., HARRINGTON, J.Y., NICHOLLS, M.E., CARRIO, G.G., MCFADDEN, J.P. RAMS 2001: Current status and future directions. Meteorology and Atmospheric Physics, 82, 5-29, 2003.

HARRINGTON J.Y., OLSSON, P.Q. A method for the parameterization of cloud radiative properties within numerical models: Implications for Arctic Cloudy Boundary Layers. Atmospheric Research, 57, 51-80, 2001.

HASTENRATH, S. Predictionof Northeast Brazil rainfall anomalies. Journal of Climate, 3, 893-904, 1990

HENESSEY, J. P. Some aspects of wind power statistics. Journal of Applied Meteorology, 16, 119-128, 1977.

MELLOR, G. L., YAMADA, T. A hierarchy of turbulence closure models for planetary boundary layers. Journal of Atmospheric Science, 31, 1791-1806, 1974.

PIELKE, R.A., COTTON, W.R., WALKO, R.L., TREMBACK, C.J., LYONS, W.A., GRASSO, L.D., NICHOLLS, M.E., MORAN, M.D., WESLEY, D.A., Lee, T.J., COPELAND, J.H. A comprehensive meteorological modeling system - RAMS. Meteorology and Atmospheric Physics 49, 69-91, 1992. RAO, V. B., M. C. LIMA, and S. H. FRANCHITO. Seasonal and interannual variations of rainfall over eastern Northeast Brazil. Journal of Climate, 6, 1754-1763, 1993. 
WALKO, R. L., W. R. COTTON, M. P. MEYERS, J. Y. HARRINGTON. New RAMS cloud microphysics parameterization Part I: the single - moment scheme. Atmospheric Research, 38, 29-62, 1995.
ZEBIAK, S. E. Air-sea interaction in the equatorial Atlantic region. Journal of Climate, 6, 1567-1586, 1993. 